International Journal of Oceanography and Hydrobiology Volume 50, No. 2, June 2021

\title{
Inter-clutch egg differences and androgenesis in rainbow trout (Oncorhynchus mykiss, Walbaum 1792)
}

by

\section{Marcin Polonis ${ }^{1, *}$, Agata Błaszczyk ${ }^{2}$, Krzysztof Jagiełło', Ligia Panasiak', Stefan Dobosz ${ }^{3}$, Konrad Ocalewicz ${ }^{1}$}

\section{DOI: 10.2478/oandhs-2021-0015 \\ Category: Original research paper \\ Received: September 14, 2020 \\ Accepted: November 16, 2020}

'University of Gdańsk, Faculty of Oceanography and Geography, Institute of Oceanography, Division of Marine Biology and Ecology, Al. M. Piłsudskiego 46, 81-378 Gdynia, Poland ${ }^{2}$ University of Gdańsk, Faculty of Oceanography and Geography, Institute of Oceanography, Division of Marine Biotechnology, Al. M. Piłsudskiego 46, 81-378 Gdynia, Poland ${ }^{3}$ Inland Fisheries Institute in Olsztyn, Department of the Salmonid Research in Rutki, 83-330 Żukowo, Poland

* Corresponding author: marcin.polonis@o2.pl

\begin{abstract}
lonizing radiation (IR) is applied to inactivate the nuclear genome in rainbow trout eggs during induced androgenetic development. However, IR-generated reactive oxygen species (ROS) may affect developmental potential of eggs and reduce the effectiveness of androgenesis. To verify this assumption, androgenetic development of rainbow trout was induced in eggs irradiated with $350 \mathrm{~Gy}$ of X-rays. Survival rates, $\mathrm{pH}$ of the ovarian fluid and activity of antioxidant enzymes, including SOD, CAT and GPx, were examined in non-irradiated and irradiated eggs originating from four females. Survival rates of androgenetic embryos developing in eggs produced by different females varied from $1 \%$ to $57 \%$ and these inter-clutch differences were significant. Eggs from female F4, which showed the highest developmental competence for androgenesis, also showed increased activities of SOD, CAT and GPx enzymes. The $\mathrm{pH}$ value of the ovarian fluid of each female was over 8 before and after irradiation, therefore it seems that radiation did not affect the ovarian fluid $\mathrm{pH}$. Considering the above-mentioned inter-clutch differences, a strong maternal effect on the effectiveness of androgenesis can be assumed. Eggs with increased activity of antioxidant enzymes before irradiation should be expected to show increased developmental competence for androgenesis.
\end{abstract}

Key words: androgenesis, antioxidant enzymes, egg quality, ionizing radiation, reactive oxygen species, Oncorhynchus mykiss 


\section{Introduction}

The quality of fish eggs, defined as their ability to be fertilized and develop into normal embryos, is affected by many internal and external factors, including maternal age and condition, photoperiod regimes, hormonal stimulation, stress, handling and feeding (Migaud et al. 2013). Furthermore, the time that elapses between the ovulation of eggs and their fertilization, known as post-ovulatory oocyte ageing, has also been proven to reduce the quality of fish eggs (Aegerter \& Jalabert 2004). For instance, in farmed salmonid species, ovulated oocytes are held in the coelomic cavity and immersed in the ovarian fluid until they are stripped. In rainbow trout, when eggs are not collected within a maximum of 5-7 days after ovulation, biochemical, histological, cellular and molecular changes in eggs may result in their reduced developmental competence (Aegerter \& Jalabert 2004). Although hatching and malformation rates (Aegerter \& Jalabert 2004; Jagiełło et al. 2018; Polonis et al. 2019) are considered the most effective indicators of fish egg quality, other biomarkers, including the distribution of lipid droplets (Mansour et al. 2007; Ciereszko et al. 2009; Polonis et al. 2019), pH of the ovarian fluid (Aegerter \& Jalabert 2004) and quality and quantity of maternal transcripts (Sullivan et al. 2015; Ocalewicz et al. 2020) have been proposed for use in assessing the developmental competence of salmonid fish eggs.

Currently, the reactive oxygen species (ROS) and oxidative stress are considered to be associated with post-ovulatory oocyte ageing, which causes an overall decline in fish egg quality (Samarin et al. 2018a). The main sources of ROS are the electron transport chain in mitochondria and the NADPH oxidase system in the cellular plasma membrane. Under normal cellular metabolism, ROS are involved in energy production, regulation of cell growth, inter-cellular signaling, and synthesis of biologically important compounds (Mantovani et al. 2003; Goud et al. 2008). However, environmental stress and ageing have been shown to increase the amount of ROS in cells, which results in reduced ATP production and irregular $\mathrm{Ca}^{2+}$ oscillation changes. Moreover, ROS cause protein degradation, spindle formation errors, DNA damage, lipid peroxidation, and an accelerated rate of telomere shortening (Sasaki et al. 2019; Tarín et al. 2000; Samarin et al. 2019a). Cellular oxidative stress occurs when pro-oxidant forces overcome antioxidant defenses. To reduce the level of ROS and their negative impact, cells use enzymatic and non-enzymatic antioxidant systems. Antioxidant enzymes such as superoxide dismutase (SOD), catalase (CAT), glutathione peroxidase (GPx) and glutathione reductase (GR) are the most important components of the enzymatic response to the oxidative stress. So far, antioxidant enzyme activities in fish eggs have been reported only for a few species such as tench Tinca tinca, common carp Cyprinus carpio and goldfish Carassius auratus (Samarin et al. 2018b; Samarin et al. 2019a,b). On the other hand, the non-enzymatic defense consists of vitamins: $E, C$ and $A$, as well as glutathione, carotenes and ubiquinol10 (Prieto et al. 2006).

One of the most important exogenous sources of ROS is ionizing radiation (IR), including gamma and $\mathrm{X}$-rays. The IR penetrates cells and the absorbed energy affects organelles, cellular components and crucial macro-molecules such as DNA, membrane lipids and proteins (Somosy 2000). The IR is mainly applied in the treatment of cancers, however, it is also effective for inactivating (damaging) maternal chromosomes when inducing androgenesis in fish (Komen \& Thorgaard 2007). During artificial androgenesis, irradiated (IR) eggs are inseminated with normal spermatozoa and develop as androgenetic haploid embryos (aHs). To recover the diploid state, androgenetic haploid zygotes are exposed to a physical (temperature, hydrostatic pressure) or chemical shock around the prophase of the first mitosis to block the first cell cleavage and duplicate paternal chromosomes (Pandian \& Koteeswaran 1998). Diploid androgenotes are fully homozygous individuals, also known as androgenetic doubled haploids (aDHs). Androgenetic $\mathrm{Hs}$ and $\mathrm{DHs}$ are used in studies on phenotypic consequences of recessive alleles. Furthermore, diploid androgenetic specimens have been used in breeding programs, production of clonal generations of fish, monosex stocks and procedures of gene mapping, genome sequencing and egg transcriptomics (Komen \& Thorgaard 2007; Ocalewicz et al. 2019). Unfortunately, survival rates of aDHs rarely exceed $10 \%$ at hatching, which limits the utility of androgenetic fish. The drastic mortality of androgenotes appears to be mainly due to the expression of lethal alleles. Furthermore, side effects of irradiation and exposure to a physical or chemical shock may also affect the survival of embryos developing in such treated eggs (Komen \& Thorgaard 2007; Polonis et al. 2019).

Although the IR applied for inactivation of maternal chromosomes may cause generation and accumulation of ROS, there is no information on potential effects of X-rays on antioxidant enzyme activities in fish eggs irradiated for androgenesis. Therefore, the main objective of the present experiment was to evaluate potential changes in the anti-oxidant defense system in rainbow trout (Oncorhynchus mykiss) eggs irradiated with X-rays for androgenesis. Eggs used in the experiment came from four females and were 
examined for size (diameters) and developmental capacity (survival of normal and androgenetic specimens). Moreover, $\mathrm{pH}$ of the ovarian fluid from each egg donor was examined before and after irradiation.

\section{Materials and methods}

\subsection{Gamete collection}

The experiment performed on 7 April 2019 was approved by the Local Committee for Animal Experiments in Gdańsk, Poland (No. 28/2015). Four females (F1-F4) and two males (M1 and M2) from the spring spawning broodstock of rainbow trout (Oncorhynchus mykiss Walbaum 1792), reared at the Department of Salmonid Research, Inland Fisheries Institute in Olsztyn, Rutki, Poland, were used as gamete donors for this research.

Prior to handling, fish were anesthetized with Propiscin (etomidate, IRŚ, Poland) at a dose of 0.5 $\mathrm{ml} \mathrm{I}^{-1}$ water. Eggs from each female were collected into separate plastic bowls and kept at $10^{\circ} \mathrm{C}$ until further manipulations. Milt from three males was collected, while avoiding contamination with urine and feces, into plastic containers. Just after collection, $1 \mu \mathrm{l}$ of milt from each male was activated with $49 \mu$ of sperm activating medium (SAM; $154 \mathrm{mM} \mathrm{NaCl}$ and $1 \mathrm{mM} \mathrm{Ca2}^{+}$, buffered to pH 9.0 with $20 \mathrm{mM}$ Tris $+30 \mathrm{mM}$ glycine; Billard 1992) and analyzed under a microscope (Nikon Eclipse E 2000) to confirm the motility of spermatozoa. For further use, milt from only two males was stored in a fridge $\left(2-4^{\circ} \mathrm{C}\right)$ until the insemination process. During this experiment, eggs were kept in the ovarian fluid until fertilization.

\subsection{Induction of Androgenesis}

Eggs from each female (ca. 3220) were divided into two batches; eggs from the first batch (ca. 2080) were irradiated for androgenesis, while eggs from the second batch (ca. 1140) were left to be fertilized and develop as normal trout (control groups). Eggs to be exposed to $\mathrm{X}$-rays were packed in separated plastic boxes with lids and transported in a cooler box $\left(\leq 4^{\circ} \mathrm{C}\right.$, ca. $40 \mathrm{~min}$ ) to the Clinic of Oncology and Radiotherapy, University Clinical Center, Medical University of Gdańsk for irradiation. Irradiation of eggs was performed with a dose of 350 Gy under the same conditions as previously described (Polonis et al. 2019). After the treatment, eggs were returned under the same conditions to the hatchery to continue the experiment.

Eggs from the irradiated and non-irradiated groups from each female were inseminated with the sperm at a ratio of $0.15 \mathrm{ml}$ of semen per approximately $150 \mathrm{~g}$ of eggs in the presence of SAM. At the fifth minute after activation, eggs were rinsed with hatchery water, while 350 min after insemination, the irradiated eggs were exposed to a high hydrostatic pressure (HHP) shock (9500 PSI for $3 \mathrm{~min}$ ) using a TRC-APV electric/hydraulic apparatus (TRC Hydraulics Inc. Dieppe, Canada) to duplicate paternal chromosomes by preventing the first cell cleavage and to produce androgenetic Doubled Haploids (aDH1-aDH4). Portions of about 312 irradiated and fertilized eggs from each female were not treated with HHP and left to develop as androgenetic haploids (aH1-aH4).

Control groups were created by fertilizing non-irradiated eggs from each female (C1-C4). Eggs from the diploid control and diploid androgenetic groups were incubated in three replicates, while eggs from the haploid androgenetic groups were incubated in one replicate in the hatching apparatus at $10^{\circ} \mathrm{C}$ under routine hatchery conditions.

\subsection{Survival of androgenetic and control embryos}

Survival rates of fish from the androgenetic and control groups were calculated at the eyed stage ( 26 days post-fertilization, $\mathrm{dpf}$ ) and at the swim-up stage (58 dpf).

\subsection{Enzyme activity assays}

\subsubsection{Preparation of egg supernatant for enzymatic analysis}

Thirty non-irradiated and 30 irradiated eggs from each female were homogenized in the phosphate buffer $(\mathrm{pH}$ 7.4) on ice using an ultrasonic probe Sonopuls HD2070 (Berlin, Germany). Homogenates were centrifuged at $10000 \times \mathrm{g}$ for $15 \mathrm{~min}$ at $4^{\circ} \mathrm{C}$. The obtained supernatants were kept at $-80^{\circ} \mathrm{C}$ until assays were performed but no longer than 1 month.

\subsubsection{Determination of antioxidant enzyme activity in irradiated} and non-irradiated eggs

Enzyme activity assays were performed as colorimetric assays in 96-well plates using a microplate reader (Molecular Devices, Sunnyvale, CA, USA). Enzyme activity was expressed as units/ml for SOD and $\mathrm{nmol} / \mathrm{min} / \mathrm{ml}$ for CAT and GPx. Samples were tested in triplicate.

Catalase assay

Catalase (CAT) activity was analyzed using a Catalase Assay Kit (Cayman Chemical Co., Ann Arbor, 
Michigan, USA). The assay was conducted according to the manufacturer's protocol. CAT catalyzes the conversion of two $\mathrm{H}_{2} \mathrm{O}_{2}$ molecules to molecular oxygen and two molecules of water (catalytic activity). CAT also shows peroxidase activity when low molecular weight alcohols can serve as electron donors, while aliphatic alcohols serve as specific substrates. This type of activity is used in the determination of enzyme activity following the reaction of an enzyme with methanol in the presence of $\mathrm{H}_{2} \mathrm{O}_{2}$. Formaldehyde is produced and measured by spectrophotometric techniques with 4-amino-3-hydrazino5-mercapto1,2,4-trizazole as chromogen (Ismail et al. 2012). The absorbance was monitored at $540 \mathrm{~nm}$.

Superoxide dismutase assay

Superoxide dismutase (SOD) activity was assayed using a Superoxide Dismutase Assay Kit (Cayman Chemical Co., Ann Arbor, Michigan, USA). The technique employs tetrazolium salt to quantify superoxide radicals generated by xanthine oxidase and hypoxanthine. The standard curve was generated using the SOD standard. The absorbance was monitored at $450 \mathrm{~nm}$.

\section{Glutathione peroxidase assay}

Glutathione peroxidase (GPx) catalyzes the reduction of hydroperoxides, including hydrogen peroxides, by reduced glutathione. The assay kit (Cayman Chemical Co., Ann Arbor, Michigan, USA) measures the GPx activity through a coupled reaction with glutathione reductase (GR). Oxidized glutathione (GSSG) is produced upon reduction of hydroperoxide by GPx and recycled to its reduced state by GR and NADPH. Oxidation of NADPH to NADP+ is accompanied by reduced absorbance at $340 \mathrm{~nm}$. The rate of $\mathrm{A}_{340}$ reduction is directly proportional to the GPx activity in a sample.

\subsection{Egg size measurement}

Portions of irradiated $(n=30)$ and non-irradiated $(n=30-33)$ eggs from each female were randomly selected before fertilization, transferred to separate PVC containers with ovarian fluid and transported from the Clinic of Oncology and Radiotherapy to the Institute of Oceanography, University of Gdańsk in a cooler box. Each egg was photographed from one side under a Nikon SMZ18 binocular with a Nikon Plan Flour $60 \times / 0.75$ lens using an Opta-Tech 5 MPIS digital camera and OptaView-IS software (Opta-Tech). Photographs were analyzed using NIS-Elements BR 3.1 and AxioVision LE software. The photographs taken were used to measure a diameter of oocytes.

\section{6. $\mathrm{pH}$ analysis}

The $\mathrm{pH}$ of the ovarian fluid of each female used as an egg donor was measured using an ERH-12-6 electrode and a CP-401 pH meter (Elmetron, Poland) at four different stages, i.e. after egg stripping, after transportation of eggs to the Medical University of Gdańsk, but before irradiation, after irradiation and just before fertilization. Each measurement was performed in triplicate.

\subsection{Statistical analysis}

Statistical analysis was carried out using SPSS statistical software (version 18; IBM Corp) for Windows. The normality was assessed using the Shapiro-Wilk test. The Kruskal-Wallis test was used to analyze differences in survival rates of androgenetic and control rainbow trout developing in eggs originating from different egg donors, $\mathrm{pH}$ values at four different stages (described above) and antioxidant enzyme activities in radiated and non-radiated eggs derived from different females. Differences in the size of radiated and non-radiated eggs originating from different females were evaluated using ANOVA with post-hoc Tukey's HSD test. Student's t-test was used to analyze differences in the activity of antioxidant enzymes in radiated and non-radiated eggs. Differences were considered significant at $p<0.05$.

\subsection{Molecular verification of androgenesis}

Microsatellite DNA analysis was performed to confirm homozygosity and exclusively paternal inheritance in androgenetic fish. The conditions of DNA extraction and amplification were the same as those described previously (Polonis et al. 2019). Three microsatellite markers (loci; OMM: 1107, 1075. 1234; Rexroad et al. 2001; Rexroad et al. 2002; Rexroad \& Palti 2003), heterozygous in sperm donors, were used to examine androgenetic offspring.

\section{Results}

\subsection{Survival rates of embryos and larvae}

Survival rates of rainbow trout from the control groups were high at every studied stage and no significant inter-clutch differences were found $(p>$ 0.05; Table 1). Despite the fairly high survival rates 
Table 1

Survival rates $(\%$, averages \pm SD) of rainbow trout from control (C), androgenetic haploid $(\mathrm{aH})$ and androgenetic diploid $(\mathrm{aDH})$ groups

\begin{tabular}{|c|c|c|}
\hline Group & Eyed stage & Swim-up stage \\
\hline $\mathrm{C} 1$ & $99.14 \pm 0.56$ & $96.24 \pm 2.21$ \\
\hline $\mathrm{C} 2$ & $95.51 \pm 0.49$ & $93.29 \pm 2.20$ \\
\hline $\mathrm{C} 3$ & $95.08 \pm 3.57$ & $93.83 \pm 4.07$ \\
\hline $\mathrm{C} 4$ & $93.77 \pm 1.01$ & $93.14 \pm 1.18$ \\
\hline $\mathrm{aH} 1$ & 46.67 & - \\
\hline $\mathrm{aH} 2$ & 3,03 & - \\
\hline $\mathrm{aH} 3$ & 69.14 & - \\
\hline $\mathrm{aH} 4$ & 67.83 & - \\
\hline $\mathrm{aDH} 1$ & $29,35 \pm 2.38$ & $7.60 \pm 0.38$ \\
\hline $\mathrm{aDH} 2$ & $4,10 \pm 1.01$ & $1.39 \pm 1.05$ \\
\hline $\mathrm{aDH} 3$ & $1,39 \pm 0.50$ & $0.24 \pm 0.27$ \\
\hline $\mathrm{aDH} 4$ & $57,14 \pm 1.80$ & $27.50 \pm 0.95$ \\
\hline
\end{tabular}

of embryos from the androgenetic haploid groups observed at the eyed stage (about 70\%), none of these individuals survived till the swim-up stage (Table 1).

Survival rates of embryos from the androgenetic diploid groups varied from $1.39 \% \pm 0.50$ to $57.14 \% \pm$ 1.80. At the swim-up stage, survival rates decreased and varied from $1.39 \% \pm 1.05$ to $27.50 \% \pm 0.95$, with the highest survival of androgenotes observed in eggs from female F4. The inter-clutch differences in the effectiveness of androgenesis were statistically significant at every studied stage ( $p<0.05$; Table 1$)$.

\subsection{Antioxidant enzyme activities}

Variation in the SOD activity was observed in non-irradiated eggs originating from different females, with the highest activity observed in eggs from female F4 ( $p<0.05$, Fig. 1a). After irradiation, the highest SOD activity was still observed in eggs F4 (Fig. 1a). However, compared with non-irradiated eggs, irradiated eggs derived from females F1 and F2 showed significantly reduced activity of SOD, while eggs from female F4 showed significantly increased activity after irradiation (Fig. 1a).

Before irradiation, a significantly higher level of CAT activity was observed in eggs from female F4. However, CAT activity in eggs F4 decreased significantly after irradiation, while it did not differ significantly in eggs from different females (Fig. 1b).

The lowest activity of GPx was observed in eggs from F1, while the highest in eggs from female F4 before irradiation and the differences were significant (Fig. 1c). After irradiation, this activity increased only in gametes derived from female F1. a)

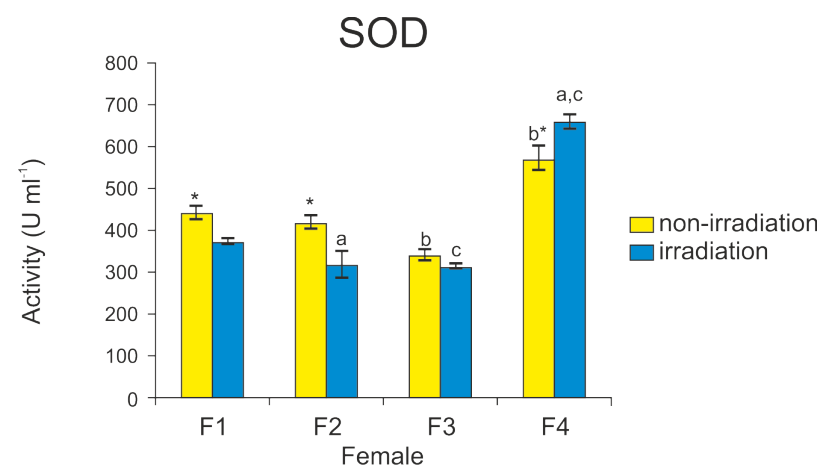

b)

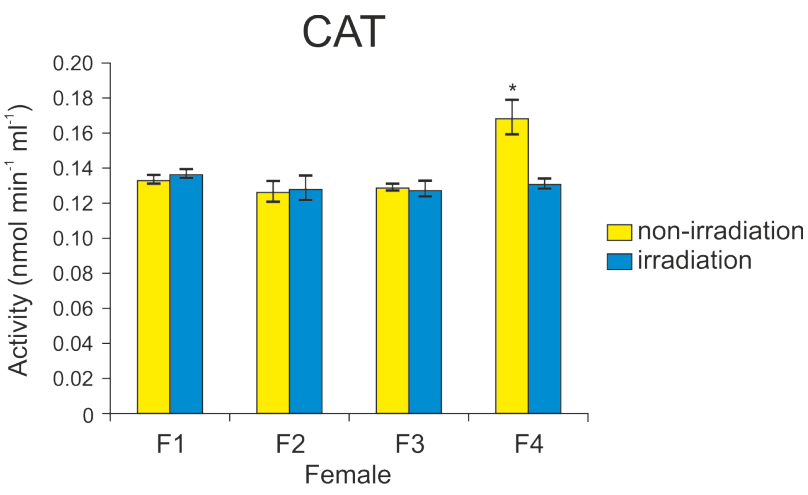

c)

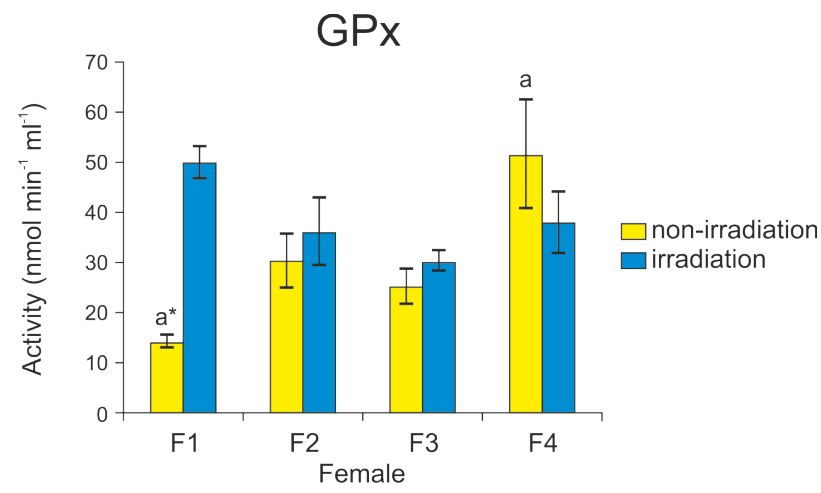

Figure 1a-c

Differences in antioxidant enzyme activity in irradiated and non-irradiated eggs between egg donor females. The same letters represent significant differences $(p<0.05)$ between antioxidant enzyme activity in eggs from different females. An asterisk indicates significant differences $(p<0.05)$ between irradiated and non-irradiated eggs from the same female. Error bars represent standard deviations. 


\subsection{Egg size measurement}

Eggs from female F4 were characterized by the smallest diameters in both variants of the experiment (non-irradiated and irradiated). Eggs from female F3 were characterized by the largest diameters in both variants of experiment (non-irradiated and irradiated; Table 2).

Table 2

Comparison of diameters ( $\mathrm{mm}$, averages $\pm \mathrm{SD}$ ) of irradiated and non-irradiated eggs of rainbow trout. An asterisk indicates lack of significant differences $(p<0.05)$ between non-irradiated eggs from females F1 and F2.

\begin{tabular}{|c|c|c|}
\multirow{2}{*}{ Female } & \multicolumn{2}{|c|}{ Groups } \\
\cline { 2 - 3 } & non-irradiated & irradiated \\
\hline F1 & $4.73 \pm 0.17^{*}$ & $4.71 \pm 0.11$ \\
\hline F2 & $4.75 \pm 0.17^{*}$ & $4.84 \pm 0.12$ \\
\hline F3 & $5.02 \pm 0.12$ & $4.98 \pm 0.16$ \\
\hline F4 & $4.01 \pm 0.21$ & $3.99 \pm 0.18$ \\
\hline
\end{tabular}

Differences in diameters of non-irradiated eggs were not significant only between eggs from females F1 and F2 (Table 2). Differences in diameters of irradiated eggs from different females were significant (Table 2).

\section{4. $\mathrm{pH}$}

The lowest $\mathrm{pH}$ values of the ovarian fluid were recorded in samples examined just after egg stripping. Then, $\mathrm{pH}$ of the ovarian fluid was gradually increasing, reaching the highest value in samples analyzed just before insemination. A similar pattern was observed in eggs from all females examined under this conditions (Fig. 2).

\subsection{Genetic verification of gamete donors and androgenetic progeny}

The analysis of the microsatellite DNA markers showed that all androgenetic progeny were homozygous in each of the studied loci.

\section{Discussion}

Although there were no inter-clutch differences in the survival of rainbow trout from the control groups, significant differences were observed in the survival of androgenotes developing in eggs produced by different females. Androgenotes that developed in eggs from female F4 showed the highest survival during embryogenesis and after hatching (about 28\%; Table 1). On the other hand, eggs from females F2 and F3 showed the lowest competence

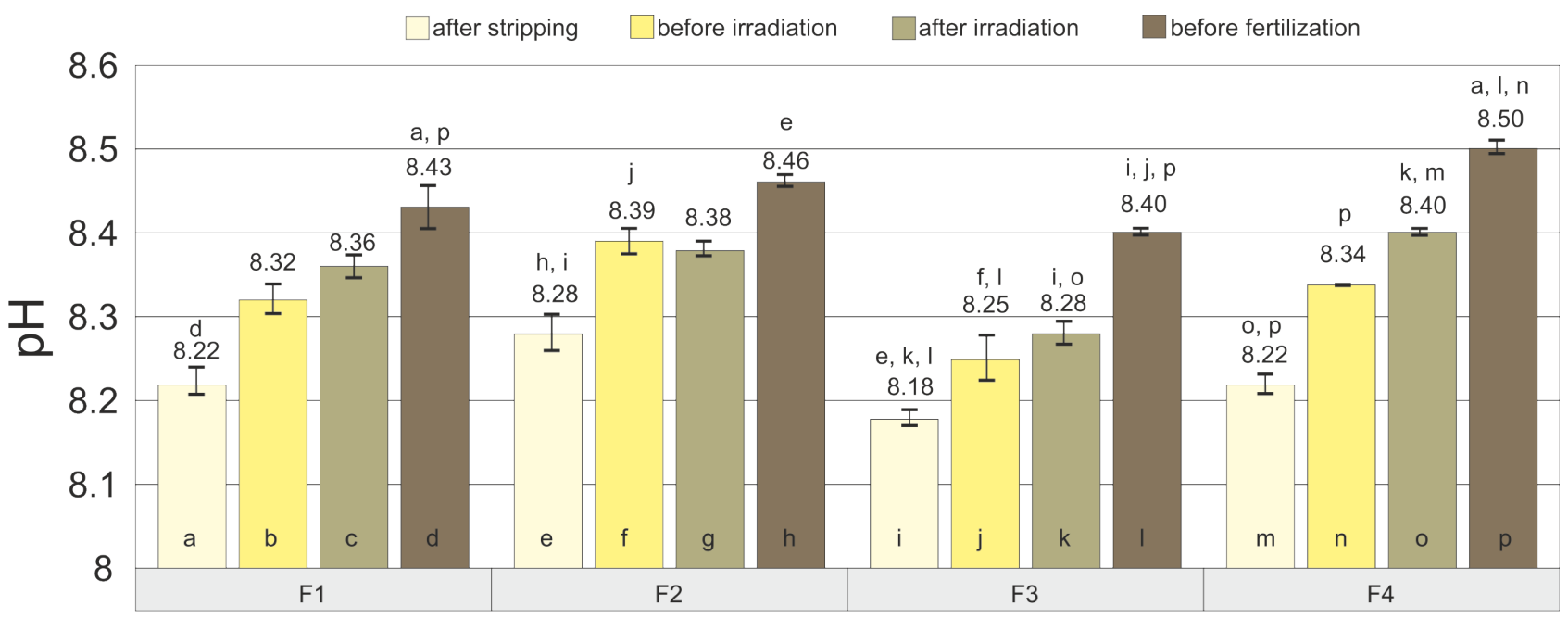

Female's number

Figure 2

$\mathrm{pH}$ values of the ovarian fluid of each female $(\mathrm{F} 1, \mathrm{~F} 2, \mathrm{~F} 3, \mathrm{~F} 4)$ whose eggs were used in the experiment, measured before and after irradiation. Significant differences in pH values are indicated by letters: a1-a4, b1-b4, c1-c4, d1-d4. Error bars represent standard deviations. 
for androgenetic development (Table 1). Variation in efficiency of chromosome set manipulations in relation to origin of gametes have been observed before when induced androgenesis and gynogenesis in salmonids and sturgeons (Ocalewicz et al. 2013; Fopp-Bayat \& Ocalewicz 2015; Jagiełło et al. 2018, Ocalewicz et al. 2020). Such inter-clutch differences in the survival rates of androgenotes could result from physiological and/or molecular differences in eggs of different origins. Results of recent transcriptomic analysis of zebrafish and rainbow trout eggs confirm inter-clutch differences in expression profiles of maternal RNA (Rauwerda et al. 2016; Gurgul et al. 2018). Moreover, eggs from female rainbow trout whose gynogenetic offspring had the highest survival rates showed altered expression of several genes compared to eggs from other females (Ocalewicz et al. 2020). Interestingly, eggs derived from female F4 were smaller than other eggs, which indicates that the size of female gametes is not related to their quality.

lonizing radiation is one of the main factors that cause cellular damage and stress through disruption of DNA integrity and formation of ROS, which are produced upon radiolysis of water molecules and effect on activity of antioxidant enzymes (Yamamori et al. 2012; Samarin et al. 2018b). Although, radiation-induced androgenesis has been performed in several fish species, including salmonids (Babiak et al. 2002; Michalik et al. 2015; Ocalewicz et al. 2013), the activity of the antioxidant defense system in irradiated fish eggs has not yet been studied. Therefore, in this research, the activity of three antioxidant enzymes in rainbow trout eggs obtained from different females were assayed before and after irradiation. Inter-clutch differences in the antioxidant enzyme activity were observed in eggs obtained from four females. Non-irradiated eggs from female F4 showed significantly higher activity of SOD, CAT and GPx compared to eggs from other examined females, which may indicate their higher resistance to ROS and thus better developmental capacity in the case of radiation-induced oxidative stress during androgenesis.

Significantly increased activity of SOD after irradiation was observed only in eggs derived from female F4. Considering that the survival rate of androgenotes developing in eggs derived from this female was the highest, it can be assumed that these eggs were more effectively protected from IR-induced oxidative stress. On the other hand, only eggs from F4 showed a significant reduction in CAT activity after irradiation. Therefore, these results may imply a compensatory response to stress and adaptation to ROS production (Samarin et al. 2018b).
A significant increase in GPx activity in irradiated eggs was confirmed for gametes from female F1. The GPx enzyme is crucial in the process of ROS detoxification by using $\mathrm{H}_{2} \mathrm{O}_{2}$ to oxidize reduced glutathione (GSH) into oxidized glutathione (GSSG; Mantovani et al. 2003). Its substantial increase in eggs derived from female F1 appears to confirm the successful response to oxidative stress. In addition, the reduction of the negative impact of oxidative stress seems to have translated into a higher survival rate of aDHs derived from this female relative to the offspring of F2 and F3 females. On the other hand, eggs from female F4 showed a large reduction in GPx after irradiation. These results may suggest that the high activity of SOD in irradiated eggs derived from this female was a sufficient response to a high level of ROS and therefore higher GPx activity was not needed. However, this hypothesis requires further investigation. GPx activity in eggs from F4 is still higher than in eggs from the two other females, which may confirm their higher quality.

In salmonids, the ovarian fluid is derived from secretory epithelia in ovaries, which are more susceptible to rapid morphological and secretory changes causing fluctuations in $\mathrm{pH}$ of this fluid (Chatakondi et al. 2012). Studies on the $\mathrm{pH}$ of the ovarian fluid conducted by Aegerter \& Jalabert (2004) and Lahnsteiner (2000) demonstrated that the viability of rainbow trout eggs was reduced as the value of ovarian fluid $\mathrm{pH}$ dropped below 8 . In our study, the $\mathrm{pH}$ value of the ovarian fluid of each female was above 8 , which together with the high survival rate of trout from the control groups confirmed the high quality of eggs used in this research (Aegerter \& Jalabert 2004; Lahnsteiner 2000). It should be noted that the $\mathrm{pH}$ value of the ovarian fluid increased with time (Fig. 2). Such a gradual change in the acid-base balance of the ovarian fluid is expected when it is removed from the body cavity and placed in contact with air (Aegerter \& Jalabert 2004). Therefore, it can be concluded that radiation has no effect on $\mathrm{pH}$ of the ovarian fluid.

\section{Conclusions}

Eggs from four rainbow trout females used in the present experiment were characterized by similar quality. However, the survival of androgenetic specimens developing in these eggs varied significantly. There were also significant inter-clutch differences in the activity of the antioxidant enzymes. Patterns of SOD, CAT and GPx activity were different in non-irradiated eggs and eggs exposed to $X$-rays for androgenesis. However, the effect of $\mathrm{X}$-rays was minor. 
The highest survival rate of androgenetic specimens was observed in eggs that showed increased CAT and GPx activities before irradiation. The high inter-clutch variation in the enzyme activity and survival of androgenetic progeny suggested the involvement of maternal genetic factor(s) enabling the effective development of androgenetic trout. There was no significant effect of X-rays on the acid-base balance of the ovarian fluid, which was considered important for the survival of androgenotes.

\section{Acknowledgements}

This work was supported by the University of Gdańsk, Poland (grant number 538-G205-B108-18). We thank Rafał Różyński from the Department of Salmonid Research, Inland Fisheries Institute in Olsztyn, Rutki, for his technical assistance during the experiment.

\section{References}

Aegerter, S. \& Jalabert, B. (2004). Effects of post-ovulatory oocyte ageing and temperature on egg quality and on the occurrence of triploid fry in rainbow trout, Oncorhynchus mykiss. Aquaculture 231(1-4): 59-71. DOI: 10.1016/j. aquaculture.2003.08.019.

Babiak, I. Dobosz, S. Goryczko, K. Kuzminski, H. Brzuzan, $P$. et al. (2002). Androgenesis in rainbow trout using cryopreserved spermatozoa: the effect of processing and biological factors. Theriogenology 57(4): 1229-1249. DOI: 10.1016/S0093-691X(02)00631-3.

Chatakondi, N.G. Torrans, E.L. (2012). The influence of ovarian fluid $\mathrm{pH}$ of stripped unfertilized channel catfish, Ictalurus punctatus, eggs on the hatching success of channel catfish $+\mathrm{x}$ blue catfish, Ictalurus furcatus $\hat{0}$, hybrid catfish eggs. J World Aquacult. Soc. 43(4): 585-593. DOI: 10.1111/j.1749-7345.2012.00577.x.

Ciereszko, A., Wojtczak, M., Dietrich, G.J., Kuźmiński, H. \& Dobosz, S. (2009). A lack of consistent relationship between distribution of lipid droplets and egg quality in hatchery-raised rainbow trout, Oncorhynchus mykiss. Aquaculture, 289(1-2): 150-153. DOI: 10.1016/j. aquaculture.2008.12.032.

Fopp-Bayat, D. \& Ocalewicz, K. (2015). Activation of the albino sterlet Acipenser ruthenus eggs by UV-Irradiated bester hybrid spermatozoa to provide gynogenetic progeny. Reprod. Domest. Anim. 50(4): 554-559. DOI: 10.1111/ rda.12521.

Goud, A.P. Goud, P.T. Diamond, M.P. Gonik, B. \& Abu-Soud, H.M. (2008). Reactive oxygen species and oocyte aging: role of superoxide, hydrogen peroxide, and hypochlorous acid. Free Radical Bio. Med. 44(7): 1295-1304. DOI: 10.1016/j. freeradbiomed.2007.11.014.

Gurgul, A., Pawlina-Tyszko, K., Bugno-Poniewierska, M., Szmatoła, T., Jasielczuk, I. et al. (2018). Transcriptome analysis of rainbow trout (Oncorhynchus mykiss) eggs subjected to the high hydrostatic pressure treatment. Int. J. Genomics. DOI: 10.1155/2018/5197126.

Ismail, N.A. Okasha, S.H. Dhawan, A. Rahman, A.M.A. Hamid, N.A. et al. (2012). Glutathione peroxidase, superoxide dismutase and catalase activities in children with chronic hepatitis. DOI: 10.4236/abb.2012.327119.

Jagiełło, K. Dobosz, S. Zalewski, T. Polonis, M. \& Ocalewicz, K. (2018). Developmental competence of eggs produced by rainbow trout Doubled Haploids (DHs) and generation of the clonal lines. Reprod. Domest. Anim. 53(5): 1176-1183. DOI: $10.1111 /$ rda.13223.

Komen, H. \& Thorgaard, G. (2007). Androgenesis, gynogenesis and the production of clones in fishes: A review. Aquaculture 269: 150-173. DOI: 10.1016/j.aquaculture.2007.05.009.

Lahnsteiner, F. (2000). Morphological, physiological and biochemical parameters characterizing the over-ripening of rainbow trout eggs. Fish. Physiol. Biochem. 23(2): 107118. DOI: 10.1023/A:1007839023540.

Mansour, N. Lahnsteiner, F. \& Patzner, R.A. (2007). Distribution of lipid droplets is an indicator for egg quality in brown trout, Salmo trutta fario. Aquaculture 273(4): 744-747. DOI: 10.1016/j.aquaculture.2007.09.027.

Mantovani, G., Macciò, A., Madeddu, C., Mura, L. Gramignano, G. et al. (2003). The impact of different antioxidant agents alone or in combination on reactive oxygen species, antioxidant enzymes and cytokines in a series of advanced cancer patients at different sites: correlation with disease progression. Free Radical Res. 37(2): 213-223. DOI: $10.1080 / 10715760303849$.

Michalik, O., Dobosz, S., Zalewski, T., Sapota, M. \& Ocalewicz, K. (2015). Induction of gynogenetic and androgenetic haploid and doubled haploid development in the brown trout (Salmo trutta Linnaeus 1758). Reprod. Domest. Anim. 50(2): 256-262. DOI: 10.1111/rda.12480.

Migaud, H., Bell, G., Cabrita, E., McAndrew, B., Davie, A. et al. (2013). Gamete quality and broodstock management in temperate fish. Rev. Aquacult. 5: 194-223. DOI: 10.1111/ raq. 12025.

Ocalewicz, K., Gurgul, A., Pawlina-Tyszko, K., Szmatoła, T., Jasielczuk, I. et al. (2019). Induced androgenetic development in rainbow trout and transcriptome analysis of irradiated eggs. Sci. Rep-UK 9(1): 1-12. DOI: 10.1038/ s41598-019-44568-7.

Ocalewicz, K., Gurgul, A., Polonis, M. \& Dobosz, S. (2020). Preliminary Identification of Candidate Genes Related to Survival of Gynogenetic Rainbow Trout (Oncorhynchus mykiss) Based on Comparative Transcriptome Analysis. Animals 10(8): 1326. DOI: 10.3390/ani10081326.

Ocalewicz, K., Kuzminski, H., Pomianowski, K. \& Dobosz, S. (2013). Induction of androgenetic development of the 
brook charr (Salvelinus fontinalis) $\times$ Arctic charr (Salvelinus alpinus) hybrids in eggs derived from the parental species. Reprod. Biol. 13(2): 105-112. DOI: 10.1016/j. repbio.2013.03.002.

Pandian, T.A. \& Koteeswaran, R. (1998). Ploidy induction and sex control in fish. Hydrobiologia 384(1-3): 167-243. DOI: 10.1023/A:1003332526659.

Polonis, M., Jagiełło, K., Dobosz, S., Rożyński, R., Kondraciuk, P. et al. (2019). Alterations in the rainbow trout (Oncorhynchus mykiss) eggs exposed to ionizing radiation during induced androgenesis. Reprod. Domest. Anim. 54(4): 712-718. DOI: 10.1111/rda.13413.

Prieto, A.I., Jos, Á., Pichardo, S., Moreno, I. \& Cameán, A.M. (2006). Differential oxidative stress responses to microcystins LR and RR in intraperitoneally exposed tilapia fish (Oreochromis sp.). Aquat. Toxicol. 77(3): 314-321. DOI: 10.1016/j.aquatox.2005.12.012.

Rauwerda, H., Wackers, P., Pagano, J.F., de Jong, M., Ensink, W. et al. (2016). Mother-specific signature in the maternal transcriptome composition of mature, unfertilized zebrafish eggs. PLoS One 11(1). DOI: 10.1371/journal. pone. 0147151

Rexroad, C.E. \& Palti, Y. (2003). Development of ninety-seven polymorphic microsatellite markers for rainbow trout. Trans. Am. Fish. Soc. 132(6): 1214-1221 DOI: 10.1577/T02086.

Rexroad, C.E., Coleman, R.L., Hershberger, W.K. \& Killefer, J. (2002). Rapid communication: Thirty-eight polymorphic microsatellite markers for mapping in rainbow trout. Anim. Sci. J. 80: 541-542.

Rexroad, C.E., Coleman, R.L., Martin, A.M., Hershberger, W.K. \& Killefer, J. (2001). Thirty-five polymorphic microsatellite markers for rainbow trout (Oncorhynchus mykiss). Anim. Genet. 32(5): 317-319.

Samarin, A.M., Samarin, A.M., Østbye, T-K.K., Ruyter, B., Sampels, S. et al. (2019a). Alteration of mRNA abundance, oxidation products and antioxidant enzyme activities during oocyte ageing in common carp Cyprinus carpio. PloS One 14(2): DOI: 10.1371/journal.pone.0212694.

Samarin, A.M., Samarin, A.M., Østbye, T-K.K., Ruyter, B., Sampels, S. et al. (2019b). The possible involvement of oxidative stress in the oocyte ageing process in goldfish Carassius auratus (Linnaeus, 1758). Scientific reports 9(1): 1-9. DOI: 10.1038/s41598-019-46895-1.

Samarin, A.M., Samarin, A.M. \& Policar, T. (2018a). Cellular and molecular changes associated with fish oocyte ageing. Rev. Aquacult. 1-12. DOI: 10.1111/raq.12249.

Samarin, A.M., Sampels, S., Krzyskow, A., Burkina, V., Kristan, J. et al. (2018b). Egg oxidation status, antioxidant enzyme activities, lipid classes, fatty acid composition profile and embryo survival rates during in vitro oocyte ageing in tench Tinca tinca (Linnaeus, 1758). Aquac. Res. 49(6): 23052316. DOI: 10.1111/are.13693.

Sasaki, H., Hamatani, T., Kamijo, S., Iwai, M., Kobanawa, M. et al. (2019). Impact of oxidative stress on age-associated decline in oocyte developmental competence. Front. Endocrinol. 10. DOI: 10.3389/fendo.2019.00811.

Somosy, Z. (2000). Radiation response of cell organelles. Micron 31: 165-181. DOI: 10.1016/S0968-4328(99)000839.

Sullivan, C.V., Chapman, R.W., Reading, B.J. \& Anderson, P.E. (2015). Transcriptomics of mRNA and egg quality in farmed fish: some recent developments and future directions. General and comparative endocrinology 221: 23-30. DOI: 10.1016/j.ygcen.2015.02.012.

Tarín, J.J. Pérez-Albalá, S. \& Cano, A. (2000). Consequences on offspring of abnormal function in ageing gametes. Hum. Reprod. Update 6(6): 532-549. DOI: 10.1093/ humupd/6.6.532.

Yamamori, T., Yasui, H., Yamazumi, M., Wada, Y., Nakamura, Y. et al. (2012). lonizing radiation induces mitochondrial reactive oxygen species production accompanied by upregulation of mitochondrial electron transport chain function and mitochondrial content under control of the cell cycle checkpoint. Free Radical Bio. Med. 53(2): 260-270. DOI: 10.1016/j.freeradbiomed.2012.04.033. 